\title{
IMPROVEMENTS IN THE CIVIL ENGINEERING FOCUSED ON THE REAL ESTATE APPRAISAL WITH THE USE OF ARTIFICIAL INTELLIGENCE AND FUZZY LOGIC
}

\author{
Surgelas Vladimir, Pukite Vivita, Arhipova Irina
}

Latvia University of Life Sciences and Technologies

\begin{abstract}
In the field of civil engineering, there are some traditional methods of property evaluation that deal with these techniques. However, there is controversy about what would bring the best performance, a greater degree of ease and clarity without presenting multicollinearity. This controversy is due to the difficulty of finding appropriate predictive variables in real estate valuation since they often do not fit the binary model, involving human subjectivity. From this, the research aims to propose improvements in the property evaluation process with the use of artificial intelligence without presenting the effects of multicollinearity and autocorrelation, to predict the value of the real estate market. The object of study is a standard 2-bedroom residential apartment with $48 \mathrm{~m}^{-2}$ located in the central area of Jelgava, Latvia, in October 2019. Therefore, the methodology uses statistical inference as an initial analysis parameter and the fuzzy logic incorporates the best association rules which are originated from artificial intelligence extracted from the apriori algorithm. Finally, the results obtained by regression and fuzzy were compared with the value in euros $\mathrm{m}^{-2}$, according to the official publication of the government of Latvia, referring to the market value of a 2-bedroom residential apartment in the city of Jelgava, Latvia, in October 2019, this government publication is the reference for this study. The statistical hypotheses that allowed its validation were accepted. In the Fuzzy model, the results indicated an excellent equivalence to market prices in relation to the traditional valuation process.
\end{abstract}

Keywords: artificial intelligence, civil engineering, fuzzy logic, rules, real estate valuation.

\section{Introduction}

Fuzzy set theory contemplates the subjectivities of the variables involved, imprecision, and uncertainty of human expression (Bustince, Herrera \& Montero, 2008). Although there is a limited number of studies on diffuse logic for real estate (Kusan, Aytekin \& Özdemir, 2010), there is a strong tendency for improvements related to imprecise knowledge representation process through Fuzzy Logic, with the support of computational modeling (Marro, Pells, 2010). Due to these subjectivities involved in the process of real estate evaluation, many of them involve the need for knowledge of the areas of civil engineering or architecture passing for decision theory. The decision theory is an interdisciplinary area of study, with definitions that relate philosophy, mathematics, and statistics, applicable to almost all branches of science, engineering, and mainly to consumer psychology.

Plous (1993) conceptualizes heuristics as general rules of influence used to arrive at their judgments in uncertainty decision-making tasks, with the advantage of using them, the reduction of time and efforts made so that reasonably good judgments are made. Heuristics reduce the complexity of the tasks of accessing probabilities and predicting values to simple judgment operations. However, according to Ferreira (2000) when using the concept of subjectivity, it is the same as working with the complex, and one must be open to understanding that subjectivity is also something changeable. And in this direction, the fuzzy theory is a good estimator. (Del Giudice, De Paola \& Cantisani, 2017) presented a study on the fuzzy logic system to evaluate some properties involving inaccurate and vague data through fuzzy logic. The study also revealed that in the value of a property, there is a difficulty in working with linear approximation. On the other hand, one of the observed factors, which may be influencing this implementation is the fact of the number of fuzzy rules, established by the generated model, grow in a geometric way, directly proportional to the number of attributes selected for evaluation of the real estate. However, this does not seem to be a problem, but there is a possible intelligent solution because the proposal follows with the help of the decision tree allied to the algorithms of artificial learning. In the order hand, the non-linear behavior of the market, this range of values needs to be flexible. In this way, it will be more appropriate to obtain fuzzy inference in the Mamdani structure. The Mamdani model proved to be a reliable method for modeling property valuation considering the variability originated in man. The Mamdani approach structured in the study can be applied in government or private applications, wherever the value of the property is needed 
(Bustince, Herrera \& Montero, 2008). Thus, this way won't be losing the scientific character as the traditional evaluation. These algorithms belong to the machine learning field.

The creation of scenarios, as well as the definition of classification rules, are indexed to the software Weka data mining systems (Eibe, Hall \& Witten, 2016). Weka is a machine learning software for data mining tasks, written in Java and developed at Waikato University, New Zealand. In this context, accordingly (Posselt, Frozza \& Molz, 2015).

Although, this market value is explained by the International Valuation Standards as an estimated value at which something must be negotiated between buyer and seller in a market transaction after prudent and non-compulsory negotiation. On this basis, the powerful linear regression method is used to assess according to the objective and availability of the information so that the hedonic method is the most used according to Pinto \& Fernandes (2018). Nevertheless, there are cases where the regression method is not very suitable due to multicollinearity situations. Thus, fuzzy logic is an appropriate tool for dealing with uncertain variables and can contribute considerably to the techniques currently used in property evaluations.

The value to be estimated is usually based on several factors in the area of study. According to Fiker (2019) there are four methods for identifying the value of properties, a) Market direct comparative data method; b) Involutive method is generally employed when there is no similar sample data; c) An evolutionary method is used when there is no similar sample data to the evaluation; d) Income method. In this context, the scientific treatment to determine the value of a property deduces from a regression equation, where the market data surveyed are analyzed by inferential statistics (Nunes, Neto \& Freitas, 2019). In research involving the engineering of valuations, the model variables are chosen, which are numerical representations of the intrinsic and extrinsic characteristics of real estate (Dantas, 2012). It is important to note the relationship between the selected variables to verify the dependencies or not between them (Darlington et al., 2012).

In that context, the fuzzy methodology has been advancing since its discovery. These advances encompass different applications in engineering, management, etc. According Hajnal (2014) a study was made in Budapest on how to link project management using fuzzy logic. As a result, it provided decision support to better estimate the project's true market value. Another example of an application of fuzzy logic whose rule associations were based on specialized knowledge, and criterion analysis by Mandami, with use of the MatLab computational tool. The authors measured the absolute mean error. This revealed a high accuracy of the obtained results and indicated the possibility of using the fuzzy model in property valuations in Turkey (Yalpir, Ozkan, 2018).

From this, the first method used to evaluate was the comparative method of market data using statistical inferences and the second method is fuzzy logic. Accordingly, Borodinecs A. et al. (2013) affirm the existing building stock in most of the European countries is relatively old and on average $70 \%$ of buildings are built before the year 1980. Despite that Jelgava is a small, calm, and beautiful city of Latvia located near to the Lielupe river. That city suffered and was destroyed by war, but rebuilt during the years under Russian rule, and nowadays became an important city of independent Latvia with a polite people. Given this, 31 samples of residential apartments are employed. The analysis of a model in the Mamdani structure is built by Infuzzy software from the Universidade de Santa Cruz do Sul in Brazil. That tool is a free software designated for showing fuzzy systems (Posselt, Frozza \& Molz, 2015).

Based on the above, the research aims to propose improvements in the property evaluation process using artificial intelligence without presenting the effects of multicollinearity and autocorrelation to predict the value of the property market. The object of study is standard 2-room residential apartment with $48 \mathrm{~m}^{-2}$ located in the center area of Jelgava, Latvia, in October 2019. For this purpose, the methodology uses statistical inference as the initial analysis parameter and Fuzzy logic incorporates the best association rules originated from artificial intelligence extracted from the apriori algorithm. Finally, the results obtained by regression and fuzzy were compared with the value in euros $\mathrm{m}^{-2}$, according to the official publication of the Latvian government regarding the market value of a 2-room residential apartment in the city of Jelgava, Latvia, in October 2019. From that to propose a new vision of artificial intelligence, fuzzy logic, and practical application for property. These Latvian government figures will be our reference available at http://liaa.gov.lv/en/business-latvia/real-estate-marketresearch. The research took place in September and October 2019. The basic tasks are knowledge of the region under study; inspection of the asset being valued; collected data; choice of methodology for the evaluation; data processing has an important point which is to use artificial intelligence and data mining to simplify the number of rules and, based on them, predict the market value established by the 
model, moreover this technical artifact will do the hard work using binary logic computational. The civil engineering inspection was carried out with a real estate agent, and sometimes with the presence of the owner.

This article is part of an ongoing thesis in Latvia.

\section{Materials and Methods}

The first method used to evaluate was the comparative method of market data, using statistical inferences in the hedonic model. The second method is fuzzy logic combined with the formulation of rules of the artificial learning algorithm. The object of this study is one of the standard 2-bedroom residential apartment with $48 \mathrm{~m}^{-2}$, located in the center area of Jelgava, Latvia, the research took place in the months of September and October 2019. Jelgava city is a small and beautiful city of Latvia located near to the Lielupe river. The city suffered and was destroyed by war, but rebuilt during the years under Russian rule, and nowadays became an important city of independent Latvia. In view of this, 31 samples of standard residential apartments are employed and both available on the world wide web. The inference statistic model was chosen with the best adjustment of the observed data and without presenting multicollinearity. The direct comparative method of market data consists in obtaining a representative sample of real estate market data with characteristics, as much as possible, similar to those of the good evaluating, using all the possible evidence and based on existing theories, acquired knowledge, common sense and other attributes and self-expertise. Initially, scientific treatment by regression analysis was used with 31 samples of 1,2 , and 3 bedroom apartments, similar and located close to the evaluation apartment, in the center area of Jelgava, Latvia, in 2019, September, and both available on the network world of computers.

The second way utilized by fuzzy logic. In this context, the Fuzzy set (Zadeh, 1999) can be established by a membership function that maps the elements of a space $X$ to a real number in the range $[0 ; 1]$ or formally, $A: X \rightarrow[0 ; 1]$. In this way, a membership function assigns each element a degree, varying between 0 and 1, that is, the function returns a value between 0 and 1 if the value of the $X$ attribute is between a lower threshold and an upper threshold. Some classes of pertinence functions are most used, for example: linear by parts (triangular and trapezoidal), Gaussian and Sigmoidal.

So, the choice of these samples is formed by similar reference properties and belonging to the regions surrounding the property evaluated. In the methodology used as an initial parameter of analysis the hedonic model, and in the second analysis, the Fuzzy method combined the incorporation of the best association rules originated from artificial intelligence by the apriori algorithm. Used the computational tool Weka Software from the University of Waikato located in New Zealand (Eibe, Hall \& Witten, 2016), by the way, basically in little words Weka is a free software for data mining.

A model in the Mamdani structure will be built in Fuzzy Software with Fuzzy Inference. Because of the non-linear behavior of the market, this range of values needs to be flexible. In this way, it will be more appropriate to obtain fuzzy inference in the Mamdani structure. Because the Mamdani model proved to be a reliable method for modeling property valuation considering the variability originated in man. The Mamdani approach structured in the study can be applied in government or private applications, wherever the value of the property is needed (Bustince, Herrera \& Montero, 2008).

In relation to the quality of the data surveyed, this study opted for: Latvian Government Office, $\mathrm{http} / / /$ liaa.gov.lv/en/business-latvia/real-estate-market-research; and experience of own researcher in the formation of value.

\section{Step one:}

The generic model of the study follows the traditional expression (1).

$$
Y_{i}=\beta_{o}+\beta_{1} \times x_{1 i}+\beta_{2} \times x_{2 i}+\cdots+\beta_{k} \times x_{k i}+\varepsilon_{i} \rightarrow=1,2, \ldots, n
$$

Where the $\beta$ coefficients are unknown parameters, and the $\varepsilon_{i}$ are random error terms.

The verification and validation of the regression model used. It follows the statistical analysis criteria:

1) Multiple linear correlation coefficient (r): $10 \%$ and coefficient of determination $\left(\mathrm{r}^{2}\right)$.

2) Regression existence test: The test is affected by the distribution of FischerSnedecor. Analysis of variance, test $\mathrm{F}$, model significance: $5 \%$. The basic hypothesis is accepted, i.e., that there is a regression of $\mathrm{y}$ in $\mathrm{X}_{1}, \mathrm{X}_{2}, \mathrm{X}_{3}, \ldots, \mathrm{X}_{\mathrm{k}}$. The significance level $\alpha=5 \%$, if $\mathrm{Fc}>\mathrm{F}$.

3) Test of the significance of the regressors: The Student's T-distribution (Tailed) was used in this case, with the basic hypothesis that the regressors are different from zero to the level of significance $\alpha=10 \%$ e $30 \%$. t-Test, Regressors, two-tailed: 30\%; Sequences z-Test: $10 \%$. 
4) Kolmogorov-Smirnov Test: $10 \%$. Thus, the hypothesis that the residues are distributed normally if $\mathrm{d}_{\max }<\mathrm{d}_{\text {critico. }}$. The value of $\mathrm{d}_{\text {critico }}$ is obtained from the table, With a significance level of $5 \%$ e $n=31$ (sample size).

5) Durbin-Watson test: 5\%. Cook Distance Test F: 0.10\%.

7) Graphical analysis of residues. Checked the trusted the: $80 \%$. A confidence interval of the estimated value: $80 \%$.

8) Variables involved in modeling:

- The dependent variable $Y$ is apartment price (EUR $\mathrm{m}^{-2}$ ); The independent variables were chosen: area $\left(\mathrm{m}^{2}\right)$, consv_ap = apartment conservation (new (1), renew (2), old (3)), consv_build = building conservation (new (1), renew (2), old (3)), number of rooms (1), (2) or (3).

9) Criteria: sanitation with medium limit $\pm 2,00 \times$ Standard Deviation; Minimum number of samples: $3 \times$ number of independents variables +3 . Extrapolations not admitted.

Step two by Fuzzy logic:

Basically, this study by fuzzy logic consists of four steps (Fig. 1). Step 1: Collect real estate market data from offers for sale of standard residential apartments and analyze the characteristics and properties of one with civil engineering inspection tecniques. Estimate the price of the square meter by comparative method with the use of statistics tools; Step 2: Simplify the number of rules established by the model, using a tree of decision; and an association's rules by artificial intelligence by Weka Software and Create the Fuzzy model for real estate evaluation; Step 3: Compare the created model in fuzzy logic results to those obtained directly in the real estate market by binary logic accordingly step 1; Step 4: analyze both results obtained in the study comparing those results with the data from the published by Latvia Government.

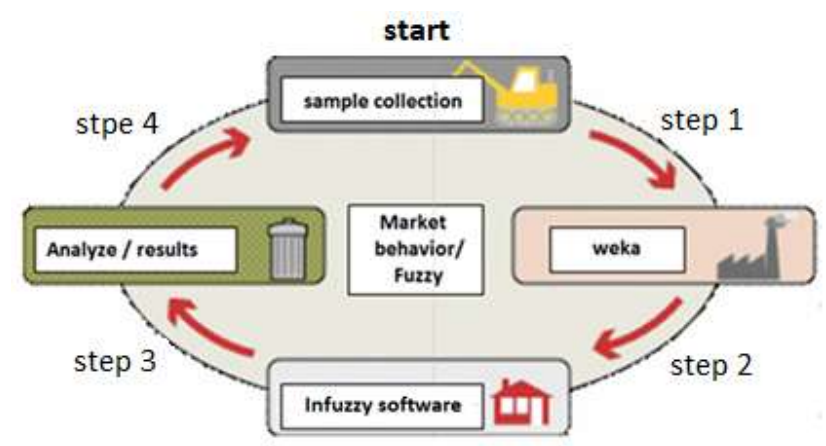

Fig. 1. The methodology used as a support tool for creating scenarios with open source software, such as Weka, Infuzzy Software, or similar.

The samples are based on offers of real estate for sale published on the worldwide network of computers. Thus, according to Fig. 2 are shown to the following steps 1 until 5.

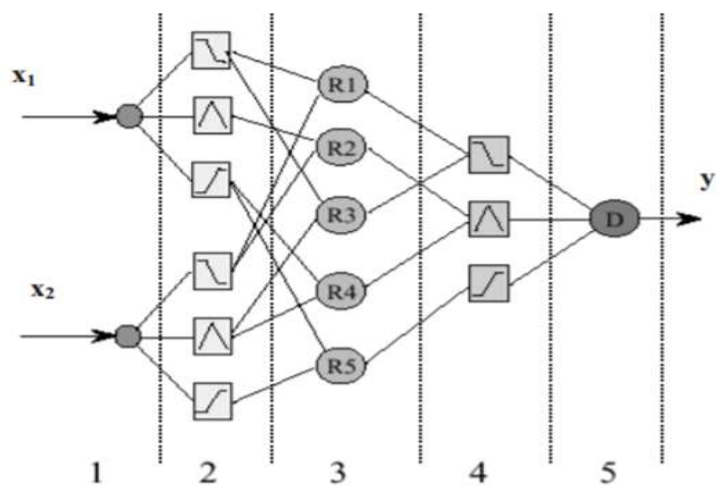

1- Inputs (variables)

2- Fuzzification of inputs (fuzzy weights)

3- Rules (from algorithm apriori by Weka)

4- Consequences of the rules (hidden layer).

5- Defuzzification (sets the numerical value of the output

Fig. 2. Fuzzy methodology of the proposal for improvements in the real estate valuation

The functions chosen are illustrated in table 1 related to variable involved in fuzzy modeling based on the computational tool with technical InFuzzy software. Thus, the relationship between the terms and values is established by a fuzzy set, in which pertinence functions model this relationship. The next step consisted in determining the rules of inference, the rules were set based on binary logical reasoning, based on scattered data from samples of properties for sale advertised on the worldwide 
computer network in the city of Jelgava. For this, we used the algorithm apriori to establish the best rules of the association. At this stage of the research, WEKA software was used to maintain the scientific seal of the analysis. In a utopian representation of reality, it would require a model with 81 rules. The mother-file computational was successfully built being aided by a text editor computational tool. That mother-file was used in the WEKA software to obtain better association rules.

Moreover, human behavior is governed by the direct influence of the environmental variables, and these are in most cases of subjective value. In our case, the real estate appraisal there is a need to consider subjective aspects, ambiguous, inaccurate, difficult to measure the value of a property.

Table 1

Classifiers - The variables involved in fuzzy modelling

\begin{tabular}{|c|c|c|c|c|c|}
\hline & Variables & Range & Classification & Degree of relevance & $\begin{array}{c}\text { Pertinence } \\
\text { function }\end{array}$ \\
\hline \multirow{12}{*}{ 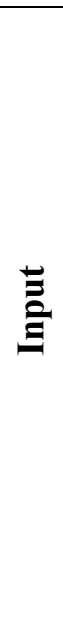 } & \multirow{3}{*}{ area } & \multirow{3}{*}[0,150]{} & small & 0,30 & left ramp \\
\hline & & & normal & $20,30,50,60$ & trapezoidal \\
\hline & & & big & 50,100 & right ramp \\
\hline & \multirow{3}{*}{ consv_ap } & \multirow{3}{*}[1,3]{} & new & 1 & discrete \\
\hline & & & renew & 2 & discrete \\
\hline & & & old & 3 & discrete \\
\hline & \multirow{3}{*}{ consv_build } & \multirow{3}{*}[1,3]{} & new & 1 & discrete \\
\hline & & & renew & 2 & discrete \\
\hline & & & old & 3 & discrete \\
\hline & \multirow{3}{*}{ rooms } & \multirow{3}{*}[1,3]{} & 1 & 1 & discrete \\
\hline & & & 2 & 2 & discrete \\
\hline & & & 3 & 3 & discrete \\
\hline \multirow{3}{*}{$\frac{\grave{E}}{\stackrel{E}{E}}$} & \multirow{3}{*}{ price } & \multirow{3}{*}[0,1200]{} & low & 150,300 & left ramp \\
\hline & & & average & $250,350,450,600$ & trapezoidal \\
\hline & & & expensive & 550,600 & right ramp \\
\hline
\end{tabular}

The defuzzification method chosen was the geometric center of the final set. In other word clouds, it is the media of centroid points weighted by the areas; and an average of the maxims, where the final value is the result of the average value of the central values activated by the rules. The discrete data were transformed into linguistic variables, that is, for each variable were attributed linguistic terms representing the numerical values of the same. The thesis is underway at Latvia University of Life Sciences and Technologies. Then, once the rules were set, we defined the methods of implication, aggregation and "defuzzification" as shown in Fig.2 completing the fuzzy system and making it fit for the inference of values.

\section{Results and Discussion}

\section{1) At the $1^{\text {st }}$ stage:}

By the analysis of the traditional statistical process, the hypotheses formulated were accepted. The estimated values $\mathrm{x}$ observed values show the adequacy of the points to the line which means a good fit of the model. The model for the dependent variable:

$$
\begin{aligned}
{[\text { price }]=1 / } & \left(1.9501 \times 10^{-3}-1.5774 \times 10^{-2} /[\text { Area }]+1.2747 \times 10^{-4} \times \operatorname{Ln}\left(\left[\text { Consv } v_{a p}\right]\right.\right. \\
& \left.-5.368 \times 10^{-4} \times \operatorname{Ln}([\text { Room }])\right)
\end{aligned}
$$

The coefficient of determination $\left(\mathrm{r}^{2}\right)$ was 0.4748 , i.e., $47.48 \%$ the market value of the properties is being explained by the model, and the adjusted coefficient of determination was $\left(\mathrm{r}^{2}{ }_{\mathrm{aj}}\right)$ was 0.4165 . The multiple linear correlation coefficient was 0.6891 indicating a STRONG correlation and between the explanatory variables and the explained. By Table 1, the analysis of variance presents the coefficient $\mathrm{F}$ calculated $8.137>\mathrm{F}$ tabulated 2.960 for the significance level of $5.000 \%$, and the significance of the model equal to $0.05 \%$. Therefore, it is accepted the hypothesis of the existence of regression. No sampling was found outside the range, there are no outliers. The results of the Kolmogorov-Smirnov 
test sample elements revealed that the greatest difference obtained: 0.0603 , with a critical value: 0.2220 for the level of significance of $10 \%$. According to the Kolmogorov-Smirnov test, at a significance level of $10 \%$, the alternative hypothesis that there is normality is accepted. Note: The Kolmogorov-Smirnov test has an approximate value when it is performed on a population whose distribution is unknown, as is the case of real estate assessments by the comparative method.

By the sequence test, the hypothesis of the randomness of the residue signs is accepted. The result of the test with deviations around the average presents lower Limit: 1.4689, Upper Limit: 1.1031, Within the normality interval [-1.2817, 1.2817] for the level of significance of $10 \%$. Value $\mathrm{z}$ (Calculated): 0,1796, Value $\mathrm{z}$ (Critical): 1,2817 (for the level of significance of $10 \%$ ), Thus by the signal test, the null hypothesis is accepted, and it can be affirmed that the distribution of the deviations around the mean follows the normal curve (Gaussian Curve). Processed elements: $n$ number of positive elements: 15; N number of negative elements: 16; Number of sequences: 20; Average signal distribution: 15.5; Standard Deviation: 2.784. Durbin-Watson Test: The Durbin-Watson test proved inconclusive for the hypothesis of the existence of autocorrelation between the residues. The calculated statistic (D) was equal to 2.4698 , located between the values of 4-du e 4-di, being $d u$ and $d i$, for $k$ explanatory variables and $\mathrm{N}$ samples to $5 \%$ of significance, equal to 1.34 and 2.66 , respectively. However, the graphic analysis showed that there is no autocorrelation between residues. The result of the Cook distance $\mathrm{F}$ test presents the following effect of each observation in the F-tabulated regression: 6,326 (for the level of significance of $0,10 \%$ ). Therefore, all the elements of the sampling passed through the consistency test. Multi-collinearity graphical verification test. The graphic result showed too that there is no multicollinearity between residues and explanatory variables. The results obtained are the following for the apartment of 2 rooms with $48 \mathrm{~m}^{-2}$ by statistical inference: Average price $747.50 \mathrm{EUR} \mathrm{m} \mathrm{m}^{-2}$, minimal 728.04 EUR m ${ }^{-2}$, maximum $768.03 \mathrm{EUR} \mathrm{m}^{-2}$. Comparing the results obtained in the study with the data of the government, we can see the existence of a similarity between these numbers. Thus, it is suggested that the result is in accordance with the prices estimated at 2019, according to the Latvian government, in this case, the region of Jelgava is 550-700 EUR m ${ }^{-2}$.

\section{2) At the $2^{\text {nd }}$ stage:}

The Fuzzy inference process is fuzzification, rule evaluation, defuzzification as output. The variables involved in fuzzy modelling are the same used in the linear regression model Fig.5, a) the dependent variable $Y$ is apartment price $\left(E U R \mathrm{~m}^{-2}\right)$; b) the independent variables were chosen: area $\left(\mathrm{m}^{2}\right)$, apartment conservation $=$ consv_ap (new (1), renew (2), old (3)), building conservation $=$ build_consv (new (1), renew (2), old (3)), number of rooms = rooms (1), (2) or (3).

1) Fuzzification / Fuzzy sets: by using pertinence functions accordingly table 1.

1.1) From the same set of samples used in linear regression, the file was successfully built by the text editor computational tool. The file format is used as the default for structuring the databases manipulated by Weka. Thus, by the software WEKA, 49 association rules were generated by the algorithm for learning/data mining. After analysed the purpose of price prediction was chosen the 7 best rules with accordance $60 \%$ (confidence).

2) Rule Evaluation are shown in an IF / THEN rule set.

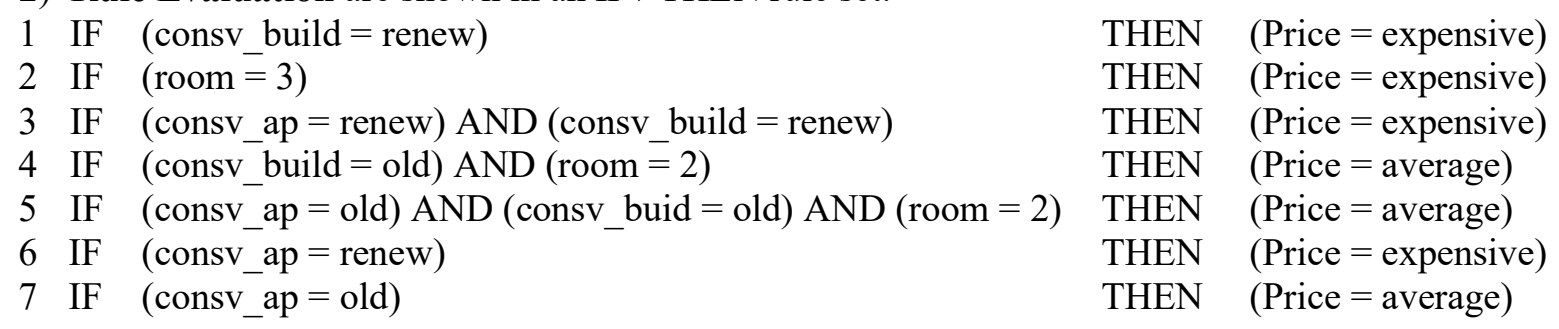

3) Defuzzification: The method of defuzzification used was the center of gravity or mass Fig.5. Price $[0,1200]$
low
average
expensive 


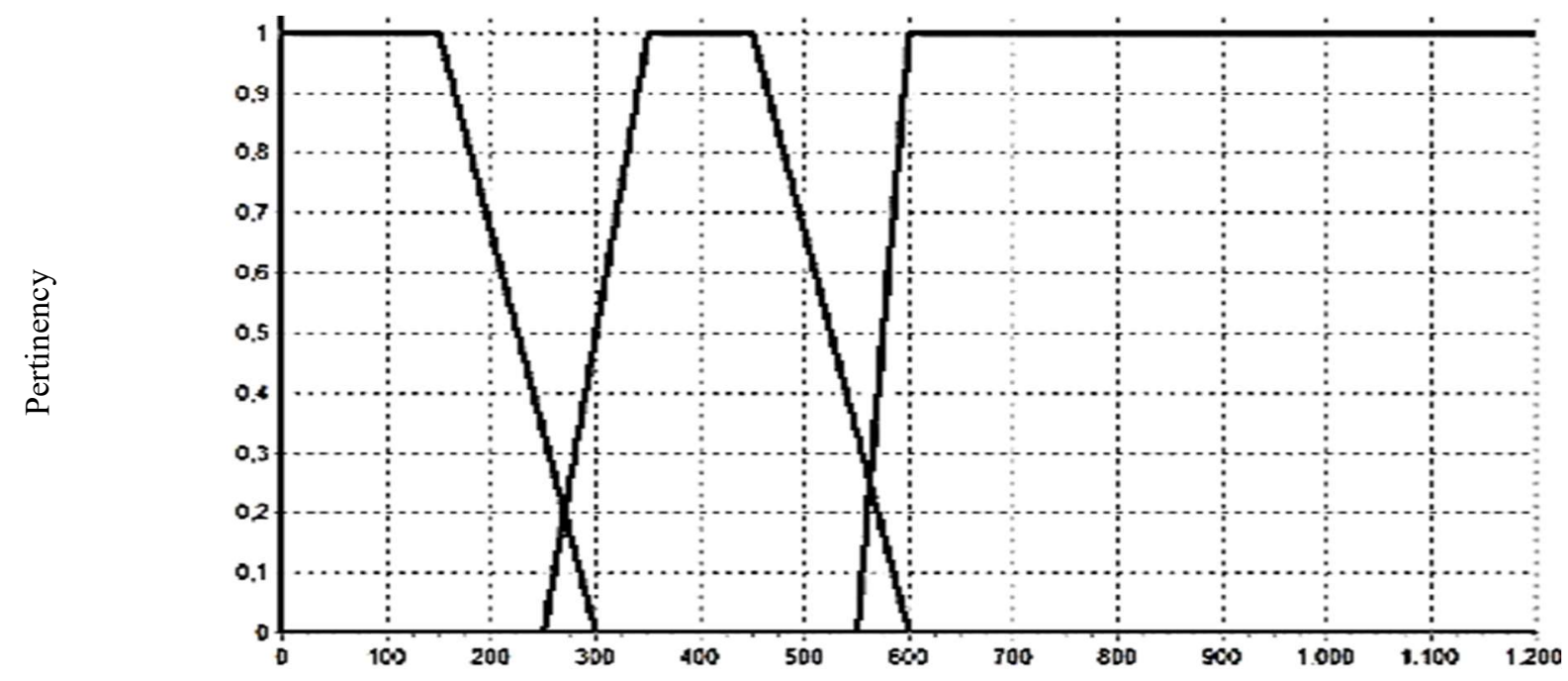

EUR $\mathrm{m}^{-2}$

Fig.5. Overview obtained - defuzzification method by the center of mass criteria

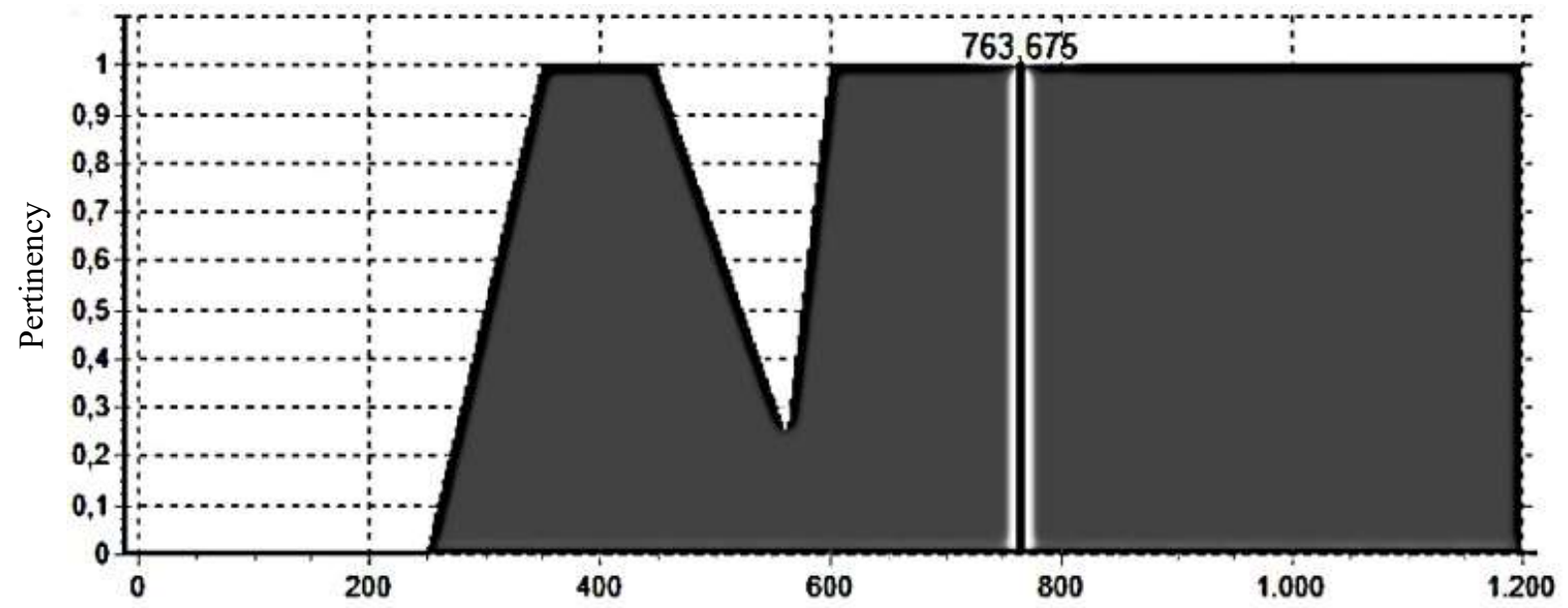

Fig.6. The result obtained: Price in EUR $\mathrm{m}^{-2}$ by the center of mass criteria (defuzzification method)

The simulations in the fuzzy model used the same variables with the same area in square meters of the property evaluating by statistics inference. In other words, consv_ap $=2$ (renew); consv_build $=3$ (old); room $=2$; area $=48.00 \mathrm{~m}^{-2}$. The value obtained in the fuzzy logic appears between the maximum and minimum intervals from binary logic, the results from the Fuzzy model will be qualified as ideal for this case. The Fig.6 shows the evaluation of the apartment by the fuzzy method resulted in values (output) $=763 \mathrm{Eur} \mathrm{m}^{-2}$. In fact, an important point of view is the source factor or trade factor $(\mathrm{Fa})$ it makes the correction of the elasticity of the information because usually the properties are offered in higher value than what is effectively transacted. Thus, the usual value is 0.9 for offered properties. On the other hand, depending on market conditions, this rate may reach 0.8 in some cases. Especially in the city of Jelgava, in some cases, this transaction factor was 0.7 , as was said by the realtors. This fact was personally verified by this researcher at the time of the surveys of the buildings used as samples. Thus, the results obtained by the regression model and by the fuzzy model have similar values, from this, Table 2 shows the comparison between the official values of the Latvian Government 2019 and the results obtained by the conventional statistical inference and the Fuzzy method composed of the best association rules derived from binary logic (apriori algorithm). 
Results with values by the conventional statistic and fuzzy model Jelgava city in October 2019 (applied the transaction factor $=0,90) /$ Value reference $\left(E U R \mathbf{~ m}^{-2}\right)$

\begin{tabular}{|c|c|c|}
\hline Government of Latvia & Fuzzy model & Regression/ Statistical Inference \\
\hline 550 (minimum) & 500 (minimum) & 655 (minimum) \\
\hline xxx---xxx & 687 (average) & 672 (average) \\
\hline 700 (maximum) & 697 (maximum) & 691 (maximum) \\
\hline
\end{tabular}

From the traditional statistical hypotheses by the hedonic model the market value was accepted and without the effect of multicollinearity. An added comparison shows too that the Fuzzy methodology used in this study incorporated with the best association rules originated from the apriori algorithm produces great results in predicting the values market in EUR $\mathrm{m}^{-2}$. These results in the possibility of using fuzzy Logic in the real estate market as an alternative. Furthermore, this is a feasible proposal for improvement in the process of valuation of real estate. Because it encompasses the human subjectivity present in the process of evaluation of real estate, and with the advantage of not causing the problem of multicollinearity or autocorrelation, both experienced largely in the traditional assessments performed by traditional hedonic models. Therefore, the results allowed us to affirm that the scattered data is useless. But aggregated data can generate rules. Rules can generate forecasts and forecasts generate knowledge. Finally, that knowledge generates income and increases aggregate the values for the economic and civil engineering sectors.

\section{Conclusions and proposals}

The study compared the use of fuzzy logic with statistical inference and data declared by the Latvian government on the market value of a standard residential apartment, both with the same characteristics involved in the variables. And so, based on the results obtained, it is concluded that there are compatibility and scientific equivalence between these market values. From this, it is possible to consider that the proposed improvements are incredibly good for real estate appraisal.

Thus, it is possible to affirm that this new heuristic vision of artificial intelligence, fuzzy logic, and practical application in the property reaches the objectives of evaluating urban properties based on requirements that involve imprecision, uncertainty, and human subjectivity. expression, ambiguous variables added to the basic criteria of civil engineering inspection. These variables were transformed into a plausible solution to determine the value of the property and without presenting the problem of autocorrelation or multicollinearity, as in many cases in the statistical inference generating results with unrealistic values.

Finally, as future proposals are advised to carry out additional research to extend the method to other property valuation markets, $\mathrm{p}$. agricultural properties.

The research is supported by the Latvian State scholarship. Special thanks to Dr. Marcello M. Veiga, from the Department of Mining Engineering (University of British Columbia, Canada). Note: Dr. Marcello Veiga is a physician in fuzzy logic and a direct student of Dr. L. A. Zadeh, the "Father of Fuzzy Logic".

\section{References}

1. Borodinecs A., Zemitis J., Rodriguez G. A., Nuorkivi A., Tatarchenko O., Voll H., Thalfeldt M., Klaas T., Petrova O., Brandt N., Kordas O., Appelgren M. (2013). Handbook on Buildings Renovation in Central Baltic Region. Riga Technical University.

2. Bustince, H., Herrera, F. \& Montero, J. (2008). Fuzzy Sets and Their Extensions: Representation, Aggregation, and Models. Springer-Verlag Berlin Heidelberg.

3. Eibe F., Hall. M.A., \& Witten, I.H. (2016). The WEKA Workbench. Online Appendix for "Data Mining: Practical Machine Learning Tools and Techniques", Morgan Kaufmann, Fourth Edition.

4. Dantas, R. A. (2012). Engenharia de Avaliações: uma introdução à metodologia cientifica (Evaluation Engineering: an introduction to scientific methodology). São Paulo: PINI (http://repositorio.unesc.net/bitstream/1/6516/1/MatheusNasárioCrema.pdf). (in Portuguese)

5. Darlington, M, Zhao, Y, Tang, L, Austin, S \& Culley, S. (2012). Measuring Information Value: key information properties and approaches to assessment. University of Bath, Bath, UK (https://purehost.bath.ac.uk/ws/files/2920648/kim23rep14mjd10_pre_print.pdf) 
6. Del Giudice, Vincenzo; De Paola, Pierfrancesco; Cantisani, Giovanni B. (2017). Valuation of Real Estate Investments through Fuzzy Logic. Buildings 7, no. 1: 26.

7. Ferreira, M. G. (2000). Gênese da concepção de subjetividade (The genesis of the concept of subjectivity). In: Ferreira, M. G. Concepções de Subjetividade em Psicologia (pp.25-61). Campinas: Pontes. (in Portuguese)

8. Fiker, J. (2019). Manual de avaliação e perícias em imóveis urbanos (Urban real estate appraisal and expertise manual). 5. ed. São Paulo: Oficina de Textos. (in Portuguese).

9. Frics I. H. (2014). Continuous valuation model for work-in-progress investments with fuzzy logic method, procedia engineering, volume 85, 2014, pages 206-213, ISSN 1877-7058.

10. Kusan, H., Aytekin, O. \& Özdemir, I. (2010). The use of fuzzy logic in predicting house selling price. Volume 37, Issue 3, 15 March 2010, Pages 1808-181315 March 2010, Pages 1808-1813. Expert systems with Applications, 2010 - Elsevier

11. Marro, A. A.; Pells, A. N. (2010). Lógica Fuzzy: Conceitos e aplicações (Fuzzy Logic: Concepts and Applications). Departamento de Informática e Matemática Aplicada (DIMAp) Universidade Federal do Rio Grande do Norte. Natal. 2010. (in Portuguese).

12. Nunes, D. B., Neto B., Paula J. de., Freitas, S. M. de. (2019). Modelo de regressão linear múltipla para avaliação do valor de mercado de apartamentos residenciais em Fortaleza, CE (Multiple linear regression model to assess the market value of residential apartments in Fortaleza, CE). Ambiente Construído, 19(1), 89-104. (in Portuguese)

13. Pinto V. H. L., Fernandes R. A. S. (2018). Análise dos preços hedônicos no mercado imobiliário residencial de Conselheiro Lafaiete, MG (Analysis of hedonic prices in the residential real estate market of Conselheiro Lafaiete, MG) Interações, Campo Grande, MS, v. 20, n. 2, p. 627-643, abr./jun. 2019 (https://www.scielo.br/pdf/inter/v20n2/1518-7012-inter-20-02-0627.pdf) (in Portuguese)

14. Plous, S. (1989). Thinking the unthinkable: The effects of anchoring on likelihood estimates of nuclear war. Journal of Applied Social Psychology, 19, 67-91

15. Posselt, E., Frozza, R. e Molz, R. (2015). INFUZZY: Ferramenta para desenvolvimento de aplicações de sistemas difusos (INFUZZY: Tool for developing diffuse system application). Revista Brasileira de Computação Aplicada. 7, 1 (fev. 2015), 42-52. (in Portuguese)

16. Yalpir, S., \& Ozkan, G. (2018). Knowledge-based FIS and ANFIS models development and comparison for residential real estate valuation. International Journal of Strategic Property Management, 22(2), 110-118.

17. Zadeh, L. A. (1999). Fuzzy sets as a basis for a theory of possibility. Fuzzy Sets and Systems. Volume 100, Supplement 1, 1999, Pages 9-341999, Pages 9-34.

Information about authors:

Vladimir Surgelas, Ph.D. candidate in Civil Engineering at Latvia University of Life Sciences and Technologies dr.engenho@gmail.com

Vivita Pukite, Ph.D. Professor at Latvia University of Life Sciences and Technologies, vivita.pukite@llu.lv

Irina Arhipova, Ph.D. Professor at Latvia University of Life Sciences and Technologies, irina.arhipova@llu.lv 